\title{
La historia como material compositivo de las novelas de Vicente Riva Palacio
}

Teresa Solórzano Ponce

IIB-UNAM

La novela de Riva Palacio sirve para analizar las relaciones entre literatura y sociedad, con especial cuidado en la función del personaje femenino.

A

ctualmente, parte de la investigación de la literatura mexicana se orienta a proponer una nueva interpretación de la producción discursiva literaria del siglo XIX a partir de renovadas lecturas, conforme a modelos teóricos originados en el siglo Xx. Así, tomando en cuenta los instrumentos teóricos y metodológicos que nos ofrece la sociología de la literatura y la teoría social del texto, nos interesa llevar a cabo un análisis de la novela de folletín mexicana del siglo XIX, con particular atención a la novelística de Vicente Riva Palacio, para comprender mejor las relaciones en- tre literatura y sociedad en el México decimonónico, lo que necesariamente nos conducirá a una compenetración mucho más rica y profunda de la historia y la cultura mexicanas.

El material escrito respecto a las relaciones entre la literatura y la sociedad es abundante. Los puntos de vista son diversos y en ocasiones contradictorios. Ante la pluralidad de enfoques de la crítica literaria creemos necesario precisar que nosotros partimos del supuesto de que el texto literario mantiene una relación específica (compleja e interna) con el contexto, entendiéndose por éste al conjunto de 


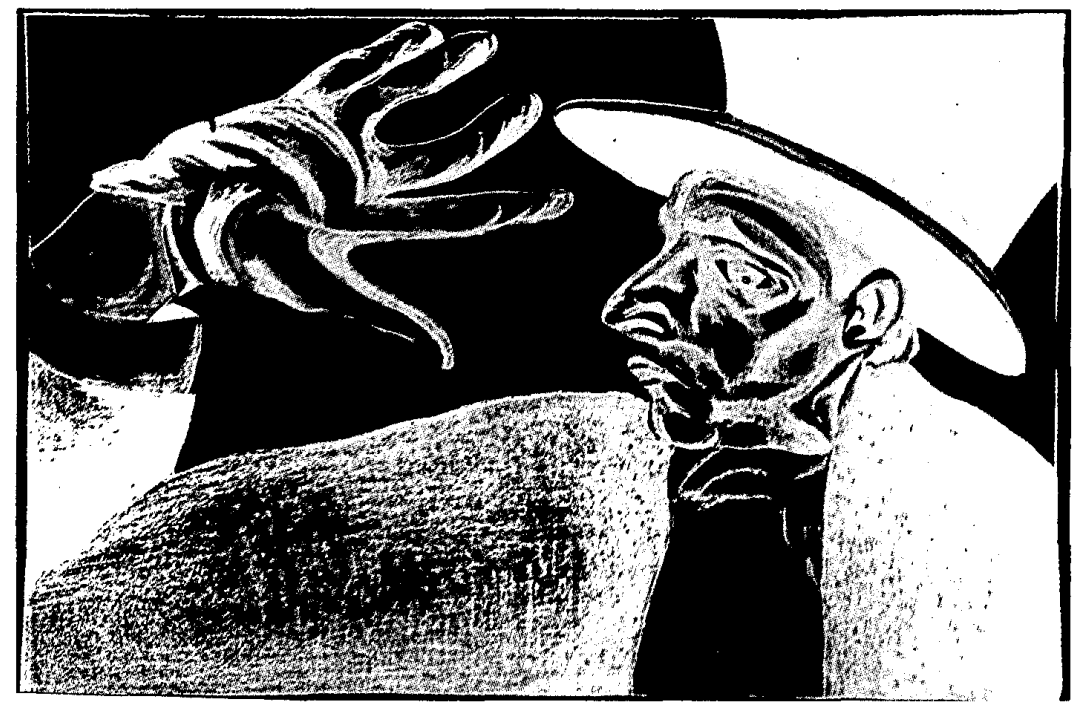

circunstancias en medio de las cuales se produce un acto de enunciación.

Ahora bien, la relación que deseamos establecer entre literatura y sociedad no es exclusivamente con el contenido de la obra literaria y con su forma externa, pues en la medida en que nos interesa la literatura como significación y sus nexos con el contexto sociohistórico y cultural, no podemos considerar el contenido como hecho autónomo separado de la forma, sino en su interrelación entre forma y contenido, es decir en su especificidad literaria. Por tanto, podemos afirmar-citando para ello a Yuri Lotman- que un contenido no puede existir, ni transmitirse fuera de una estructura, y por lo mismo el dualismo de forma y contenido debe sustituirse por el concep- to de que una idea se realiza en una estructura adecuada y que no existe al margen de esa estructura. ${ }^{1}$

Asimismo, debemos tener presente, para el estudio de las relaciones entre literatura y sociedad, las complejas y conflictivas situaciones socioculturales en las que se dęsenvuelve la literatura como parte integral de la cultura general de un pueblo. La postura ideológica de una sociedad dada en un momento histórico específico determina la manera de enfrentar los proble. mas sociales, económicos y políticos, y de ahí la importancia de estudiar los aspectos ideológico-culturales de la obra literaria como parte testimonial de la historia y de la sociedad. Así, los

' Lotman, Estructura, 1970, p. 23. 
códigos ideológico-culturales preexistentes se articulan al ser incorporados en un texto literario conformando sig. nos, y es la organización artística de estos signos la que da lugar al surgimiento de la obra literaria que, por otra parte, no es más que el espacio en el que con. fluyen el acto de la escritura y el acto de la lectura. Es decir que un texto literario sólo existe como tal, siempre y cuando se encuentre en relación de producción y génesis, o bien en relación de lectura y función. ${ }^{2}$

El resaltar la necesidad de tener presentes los procesos de génesis y función de la obra literaria no nos de. be hacer olvidar que entre la génesis social de la obra y su función social se encuentra situado el objeto literario o artístico, cuya estructura y funcionamiento interno nos interesa particularmente estudiar.

Con las consideraciones anteriormente expuestas resultará fácil percatarse de la necesidad de tener presente en todo momento de nuestro análisis de las novelas de Vicente Riva Palacio los conceptos de génesis, estructura y función de la obra. Sin embargo, y más que nada por razones de extensión, nos ocuparemos únicamente del aspecto de la función de la novela, ${ }^{3}$ pues es en la relación obra-lector donde la novela de folletín alcanza su más completa significación, además de que sea el mismo estudio de la función ideoló-

\footnotetext{
${ }^{2}$ Ferraras, Fundamentos, 1970, p. 12.

3 Para el conocimiento de mi análisis de la novela de Riva Palacio en sus tres facetas: génesis, estructura y función, remito a los interesados a mi tesis de maestría en letras mexicanas: "La propuesta", 1991.
}

gica de la novela de Riva Palacio lo que nos llevará a la mejor interpretación sociohistórica y cultural de su época, así como al cabal y justo reconocimiento del valor literario de su obra novelesca.

\section{LA FUNCIÓN IDEOLÓGICA DE LA NOVELA de Vicente Riva Palacio}

La novela de folletín o novela popular cumple de manera preponderante una función recreativa para llenar el tiempo libre de los lectores, así como para calmarles la angustia provocada por la complejidad de la vida diaria; pero al mismo tiempo cumple también una función ideológica, tan importante o más que la primera, como en el caso de Vicente Riva Palacio, quien se valió de la novela histórica romántica y de aventuras para difundir y defender los principios liberales en el terreno politico, en el orden social, en las normas morales más tradicionales; principios y normas que fundamentarian el orden, el progreso y el bienestar general.

La novela popular, para dar cabal cumplimiento a su función politizadora y moralizadora, se sirve una y otra vez de una serie de recursos formales reconocibles en la estructura de la obra (suspenso, golpes de efecto, $k i t s c h$, etc.), sin que la continua repetición de tales recursos les haga perder su efecto; por el contrario, es precisamente el carácter reiterativo de este tipo de novelas lo que las hace tan atractivas para el público consumidor, derivándose de ahí su enorme capacidad de transmitir mensajes en forma tan penetrante. 
De esta manera, Riva Palacio sacrificó, en su afán educativo, la perfección literaria en la búsqueda de la comunicación efectiva y así procuró conseguir la intriga sugerente asociada a la intensidad melodramática, ${ }^{4}$ sin que por ello omitiera incluir en sus novelas, documentos históricos y descripciones auténticas de la etapa colonial, obtenidas de fuentes históricas fidedignas, con el objeto de dar mayor validez y verosimilitud a su relatos.

Así, apegándose a las necesidades estructurales del folletín, Riva Palacio construye a sus personajes carentes de una psicología definida o profunda, pues su preocupación la situó, no en la psicología de esos personajes, sino más bien en la de los lectores a quienes pretendía dirigir su mensaje. Es así que no maneja individuos con psicología propia sino alegorías esencialmente morales: generosidad, piedad, nobleza, valentía, compasión, tolerancia, honor, amor, justicia, libertad.

Por tal motivo, las contradicciones y conflictos internos de los personajes tendrán que buscarse en sus aliados o en sus oponentes. No son individuos sino personajes colectivos construidos

\footnotetext{
${ }_{4}^{4}$ Vicente Riva Palacio (1832-1896) escribió siete novelas: Calvario y Tabor en 1868, la única de sus novelas de tema contemporáneo y en la cual resalta la figura del chinaco como símbolo y representación nacional; todas sus otras novelas son de tema colonial: Monja y casada, virgen y mártir; Historia de los tiempos de la Inquisición; y Martín Garatuza. Memoria de la Inquisición son de 1868; Las dos emparedadas. Memorias de los tiempos de la Inquisición y Los piratas del Golfo fueron publicadas en 1869; La vuelta de los muertos data de 1870, y Memorias de un impostor. Don Guillén de Lampart, rey de México, es de 1872.
}

en un sistema de oposiciones y semejanzas maniqueas. Los personajes, para ser interpretados como tales, deben ser estudiados como agrupamientos o conjuntos que en la última instancia son uno solo. ${ }^{5}$ En otras palabras: "Una suerte de universo agobiante en el cual el bien y el mal derivan constantemente el uno del otro y no cesan de alimentarse recíprocamente. Conflicto maniqueo, sí, pero también síntesis que confiere todo su sentido a esta lucha." 6

\section{EL PERSONAJE FEMENINO COMO SIGNO CENTRAL EN LA COSMOVISIÓN de Riva Paiacio}

Riva Palacio, al decidirse a escribir novelas, dirigió su interés a un público compuesto por hombres y mujeres de la clase media que no eran propiamente intelectuales, un sector susceptible de recibir y apropiarse de su mensaje concientizador.

Ahora bien, Riva Palacio mostró particular interés en el sector femenino del público lector, al que parece dirigirse expresamente siguiendo para ello, además de su natural intuición, las observaciones formuladas por Ignacio M. Altamirano: "Adoptemos para la leyenda romanesca la manera de decir elegante, pero sencilla, poética, deslumbradora si se necesita, pero fácil de comprenderse por todos y particularmente por el bello sexo, que es

\footnotetext{
5 Véase Rivera, Folletín, 1968, apartado so bre omnipotencia y bipolaridad relativizada, pp. 34-39.

${ }^{6}$ Ibid., p. 39.
} 
el que más lee y al que debe dirigirse con especialidad, porque es su género." 7

Las mujeres eran grandes lectoras de novelas desde el tiempo de $A$ madís de Gaula y, como lo apunta la doctora Díaz y de Ovando, ya desde entonces sabían llorar. ${ }^{8}$

La afición de las mujeres por las novelas adquirió su mayor auge durante el romanticismo, periodo en el que no sólo las leyeron, sino también las escribieron como George Sand y Flora Tristán.

La preocupación por proporcionar lectura a las mujeres corresponde al interés social del romanticismo por educar a la mujer.

Este público femenino que leía tantas novelas, muy probablemente porque en ellas las mujeres resultaban ser siempre heroínas, o inspiradoras de apasionados amores, o porque los protagonistas eran jóvenes hermosos, o bien porque les permitía evadirse de la realidad, no podrían menos que conmoverse e identificarse con los sufrimientos de las víctimas de las historias y sus defensores; llorarían con doña Blanca, protagonista de Monja y casa$d a$, virgen y mártir, encerrada en el convento, sin vocación monacal por la avaricia de su hermano don Pedro, compadecerían a doña Esperanza perseguida y secuestrada por sus enemigos en Martín Garatuza y, en fin, compartirían con todas las heroinas y víctimas sus experiencias y recibirian de ellas una importante lección.

${ }^{7}$ Altamirano, Literatura, 1949, p. 68.

8 Véase Díaz y de Ovando, "Gran literato", 1958, pp. 55-57.
La compasión era un excelente medio para que se captase el mensaje que se deseaba transmitir, pero además Riva Palacio creía que las lectoras que ya contaban con una cierta cultura podrían descubrir en sus novelas las ideas reformistas que impregnaban sus obras y ellas a su vez las comunicarían más tarde a sus hijos.

Asimismo, estas novelas que sustentaban principios liberales, pretendían también preservar una estructura social, fundada sobre una moral cristiana tradicional, que asimilaría fácilmente cualquier tipo de lectora y que vendría a formar parte de su vida y de su educación.

De tal forma, y puesto que Riva Palacio mostraba tan gran interés en conmover e influir en el público femenino, creemos que debe haber prestado especial atención a la creación de los personajes femeninos de sus novelas. La esmerada configuración de éstos permite que se articulen en ellos la mayoría de los códigos ideológico-culturales, presentes en las narraciones y por consiguiente podemos afirmar que el signo central del texto de Riva Palacio es el personaje femenino.

\section{EL PERSONAJE FEMENINO Y LOS CÓDIGOS IDEOLÓGICO-CULTURALES}

Los personajes femeninos están construidos en un sistema de oposiciones y semejanzas; en su conjunto conforman un solo personaje conflictivo y contradictorio capaz de transmitir la cosmovisión de Riva Palacio.

La estructura espacial del texto está dividida en dos subespacios, campos 
semánticos separados por un límite, cuya característica fundamental es su impenetrabilidad. ${ }^{9}$

En un texto como el de Riva Palacio, esquemático y arquetípico, podría pensarse que los personajes solamente pueden pertenecer y movilizarse dentro del espacio que les marca el límite. Sin embargo éstos, específicamente el personaje femenino, están capacitados para traspasar el límite que separa el campo semántico, ocasionando así el o los acontecimientos de la novela en los términos en los que Lotman habla del acontecimiento. ${ }^{10}$

De esta forma, a partir de un eje básico bueno-malo (de orden moral) se van entrelazando otras oposiciones, segmentos semánticos del espacio textual en los que se movilizan los personajes y que dan pie a la construcción de la imagen del mundo transmitida por la obra de Riva Palacio.

\section{El personaje femenino y la figura masculina}

Las heroínas de las novelas de Riva Palacio son ejemplos típicamente románticos: dulces, inocentes, fieles, puras, sensitivas y capaces de los mayores sacrificios, y de una belleza espiritual en conformidad con su hermosura fisica.

No obstante, la belleza externa no es privativa de las heroínas, las villanas en las narraciones son poseedoras de una extraordinaria y seductora her282.

9 Véase Lotman, Estructura, 1970, pp. 270 -

io Ibid., pp. 283-291. mosura, con la que ocultan sus tendencias diabólicas y a un mismo tiempo atraen víctimas a sus redes.

La mujer es una criatura celestial (ángel del bien o ángel del mal). La procedencia angelical de la mujer le ofrece la posibilidad de crear el cielo o el infierno para el enamorado.

Enmarcando a las ideas opuestas de bien y mal, cielo e infierno, ángel y demonio, se encuentra la oposición ideal-realidad. La personificación malvada en el texto (doña Luisa, doña Catalina, doña Ana, doña Inés) es mucho más compleja que la figura heroica (doña Blanca, doña Esperanza, doña Julia, doña Laura o Alejandra) puesto que en las villanas existen sentimientos opuestos y contradictorios, amory odio, anhelos de venganza y de arrepentimiento, valor y cobardía; este carácter contradictorio de la villana le da mayor cercanía a la realidad. Así, la mujer desidealizada se constituye en una decepción para el hombre, quien le atribuye entonces un sentido de maldad. Sin embargo, la naturaleza angelical de la mujer no se pierde totalmente, pues el arrepentimiento y des. pués la muerte o la reclusión (muerte social) la devuelve a su verdadero ser celestial.

La juventud, al igual que la belleza física, es caracteristica común entre heroínas y villanas; sólo las aliadas de ambas partes pueden localizarse en la mediana o avanzada edad, a diferencia de la relación héroe-villano en la que, si bien el héroe es siempre un hombre joven, el villano suele ser por lo general un hombre viejo o por lo menos bastante mayor que la víctima.

La juventud en heroínas y villanas 
se hace obligatoria porque la mujer está en la búsqueda de un lugar en la sociedad. El espacio social ubicado en las oposiciones abierto-cerrado, adentro-afuera, otorga a la mujer los espacios cerrados: habitación, casa, iglesia, convento; mientras que al hombre le pertenecen los espacios abiertos: atrios, plazas, calles, campos. Del espacio cerrado se deriva la situación social de la mujer. Las oportunidades que le ofrece la vida no pueden ser otras más que el hogar paterno, el matrimonio o el convento; cualquier otra perspectiva la colocaría fuera de la sociedad.

La definición de la posición adentro-afuera de la sociedad se lleva a cabo durante la juventud de la mujer, situación que una vez definida es irreversible, aún en los casos que podrían tener una justificación, como en el de la Matilde de Calvario y Tabor, joven honrada, casada, madre de dos niños, seducida bajo amenaza y que sin embargo no puede volver jamás a recuperar su lugar de esposa y madre en la sociedad; o bien la madre de doña $\mathrm{Ca}$ talina en Martín Garatuza, nacida de amores ilícitos, abandonada, educada por un militar en forma viril, quien decide obtener ventajas de su hermosura ante los hombres, camino que la lleva a convertirse en aliada principal de los villanos. La única fuerza liberadora de la mujer, una vez determinado su destino, es la muerte física, como en el caso de la mulata Luisa en Monja y casada..., o de doña Inés en Las dos emparedadas, o de la muerte social como le sucede a doña Ana en Los piratas..., o doña Catalina en Martín Garatuza, quienes se ven forzadas a in- gresar al convento para expiar sus culpas.

La apertura del espacio para el hombre da flexibilidad a la fijación de la edad del personaje, héroe o villano, y multiplica también las opciones para ser reconocido dentro de la sociedad. Su libertad de movimiento y su facilidad de acepción social, esquematiza al personaje inmovilizándolo en buena medida y sólo excepcionalmente se encuentra en un mismo sujeto la contradicción, teniendo que recurrir a menudo a los agrupamientos del personaje con sus aliados para establecer los conflictos internos de la persona representada. En cambio la mujer, especialmente encerrada en rígidos patrones sociales, abre para el personaje femenino un cambio más vasto de movimientos en la novela, permitiéndole traspasar el límite de lo prohibido.

La mujer es tratada en las novelas de Riva Palacio en forma paternalista. A su lado siempre hay un hombre bueno que la ayuda y defiende. Ellas permanecen pasivas ante la vida y su única defensa es la virtud. Las que toman sus propias decisiones y participan en forma activa en la acción (doña Luisa en Monja y casada..., doña Ana en Los piratas..., doña Catalina en Martín Ga. ratuza, o bien doña Inés en Las dos emparedadas) son castigadas por su actitud viril. Así, a la oposición hombre-mujer corresponde la combinación actividad-pasividad. La pasividad, cualidad representativa de la mujer, introduce al personaje femenino en la polarización del bien y del mal. De tal forma que la mujer pasiva es buena y su bondad merece ser premiada, su recompensa será el matrimonio y por 
consiguiente el reconocimiento pleno de la sociedad (doña Esperanza en Martín Garatuza o Alejandra en Calvario y Tabor); en cambio la mujer activa es mala y por tanto deber ser castigada y su castigo consistirá en la muerte fisica o en el rechazo social. La mujer es una aliada del hombre, si bien nunca ha de tomar su lugar ni sus características si no quiere perder su valía ante los ojos masculinos.

Las oposiciones de actividad-pasividad y de pecado-arrepentimiento son esenciales en el texto de Riva Palacio pues de estas polarizaciones se desprenden los verdaderos acontecimientos de la novela.

\section{El personaje femenino $y$ el acontecimiento novelesco}

El papel malvado de las villanas provoca que las mujeres se salgan de los limites establecidos para su sexo (castidad, igenuidad, abnegación, honestidad, pasividad, fidelidad, etc.). La transgresión de los límites permitidos, junto con las acciones malvadas que desempeña o desencadena en el transcurso de la trama, conforman los rasgos que caracterizan al personaje villano, y por lo mismo el retorno a los límites admitidos para la mujer y el arrepentimiento de las acciones negativas cometidas en la acción, constituyen un acontecimiento en la vida del personaje malvado, puesto que transita del terreno del mal al campo del bien, transformándose finalmente en un personaje heroico como en el caso de doña Catalina en Martín Garatuza, quien al influjo del amor que siente por don Leonel llega al reconocimiento y arrepentimiento de su proceder anterior, deseando tan sólo el perdón del hombre amado, ya que no puede aspirar a la realización de este amor. La confesión espontánea de sus faltas y la humillación de su natural altivez ante don Leonel le permiten alcanzar el perdón del amado y su posterior purificación en el ámbito del claustro.

Por su parte doña Luisa, que ha seducido, intrigado, delatado, traicionado y asesinado con el propósito de satisfacer sus pasiones e intereses, conoce la gravedad de sus faltas por primera vez delante de una de sus principales víctimas: la infeliz Blanca atormentada por la Inquisición.

¡Oh! Yo no sabía lo que era un remordimiento y es peor, sí, es peor que todos los tormentos de la Inquisición.

¡Ah! -dijo arrodillándose cerca de Blanca y tomando una de sus manosPerdóname, perdóname pobre criatura, cuanto te he hecho padecer; yo he sido una pantera, pero me arrepiento. ¡Dios mío me arrepiento! Quisiera mil veces sufrir lo que sufre esta desgraciada, primero que haber cometido los crimenes que llevo sobre mi conciencia, Jesús, y qué negra está la noche de mi conciencia... ${ }^{11}$

Las dos se encuentran encerradas en las cárceles de la Inquisición en la misma celda; sin embargo, Luisa será puesta próximamente en libertad, ya que la falsedad de los motivos que la tienen prisionera han sido descubiertos. Luisa, arrepentida procura la salvación de doña Blanca cediéndole su lugar en la salida y así doña Blanca, cu-

1 Riva Palacio, Monja, 1974, vol. II, p. 239. 
bierta por un manto, consigue escapar de su prisión, mientras Luisa tendrá que sufrir, sin imaginarlo, la suerte que esperaba a doña Blanca, es decir la muerte en el garrote. Luisa en esta muerte aunque involuntaria pero por medio de la que libra a su víctima de una injusticia más, logra la redención y purificación de su espíritu, martirio que le devuelve su naturaleza angelical primaria perdida en las circunstancias de la vida.

Si bien son acontecimientos importantes de la narración, el más significativo en el texto de Riva Palacio será el momento de rebeldía de la dulce, sumisa y abnegada Blanca, encerrada en el convento y obligada a profesar por voluntad imperiosa de su hermano; momento en el que decide violentar su actitud pasiva natural y transgredir todos los límites de lo prohibido huyendo del convento en el que ha sido depositada por don Pedro.

Es necesario -exclamó-, es necesario salir de aquí. Sí, saldré, y si al fin el Arzobispo relaja estos vínculos que yo por mi voluntad no he formado, mejor. Si no, viviréignorada, desconocida, pero libre, yo no tengo ya obligación de estar aquí. El pontífice ha dicho que si los votos me fueron arrancados por la fuerza y contra mi voluntad sea yo libre y nadie mejor que yo sabe cuanto esfuerzo me ha costado tomar el velo. La condición del papa está cumplida y yo soy libre aunque mil obstáculos se pongan por los hombres. ${ }^{12}$

Doña Blanca, como heroína y víctima de Monja y casada..., se ubica en

12 Ibid., vol. II, p. 51. el espacio del bien asociado a la pasividad, como ya se ha señalado. Su transformación de personaje pasivo a personaje activo es doblemente trascendental porque es el único personaje no sólo femenino, que en su calidad de bueno traspasa sus propios límites, rompimiento que desenlaza una serie de peripecias acumuladas con mayor rapidez que la que se había planteado anteriormente en la narración. La huida de doña Blanca a través de espacios abiertos (que no le corresponden), de calles, alamedas y campos, le atraen la persecución de la Inquisición y finalmente la muerte.

El personaje de doña Blanca, que nunca pierde sus virtudes de heroína, muere antes que su honra sea mancillada por su raptor el bandido Guzmán. Con esta muerte el personaje en última instancia es castigado por el autor, sin que por ello deje de hacer valedero en todo momento y en todos sentidos su nombre de Blanca.

Doña Blanca logra salvarse de la Inquisición, del poder judicial, de sus múltiples perseguidores, y podría haber sido feliz pues se casa con el hombre al que ama, recupera la libertad y la salud perdidas en las cárceles del Santo Oficio. Tendría que vivir aislada y olvidada de la sociedad y renunciar a sus riquezas, pero se le ofrecía una posibilidad de vida; y sin embargo, el personaje es castigado (despeñándose en la barranca de la Monja maldita) no por ignorar las disposiciones de los representantes eclesiásticos (con excepción del papa) ni por su enfrentamiento con el aparato represivo de la Inquisición o del poder judicial, sino por la desobediencia manifestada ante 
las decisiones (aunque injustas) tomadas por la autoridad paterna o masculina, representada en este caso por su hermano Pedro.

El proceder autónomo de Blanca deshonrará ante los ojos de la sociedad, no sólo a su persona sino a la fama $y$ al buen nombre de su familia; falta que, tanto para la sociedad colonial como para la sociedad del siglo XIX, no podía quedar sin castigo, y asi toda la fuerza dramática se concentra en la escena final en la que doña Blanca muere defendiendo su honra, acción que sirve de castigo pero al mismo tiempo de redención por su desobediencia y de regreso a su papel inmóvil y único en el bien. Castigo y redención que por supuesto encierran una enseñanza moral para la mujer en el final trágico de la noble y desgraciada Blanca.

\section{El personaje femenino}

\section{y la convención amorosa}

Una vez establecidas las oposiciones que rigen al binomio hombre-mujer en el ámbito social dentro del mundo narrativo de Riva Palacio es conveniente señalar las normas que definen el juego del amor en la pareja narrativa.

La relación amorosa entre el hom. bre y la mujer está planteada en el texto siguiendo muy de cerca las convenciones utilizadas en la comedia española de los Siglos de Oro; es así que los personajes masculinos y femeninos adquieren la categoría y el funcionamiento de las figuras del galán y la dama de la comedia de capa y espada.

El galán junto a la dama y el gracioso fueron la base de toda intriga teatral de la comedia española, figuras cuya fun- ción fundamental es enredar y desenredar los hilos de la trama para que mantengan el suspenso hasta el final y de esta forma ganar la atención del público.

Las características más generalizadas para el galán son: valor, generosidad, audacia, capacidad de sufrimiento, idealismo, buena presencia física, constancia y linaje. Para la dama: belleza, linaje, entrega apasionada al amor. Celos, amor, honor, son los móviles que los acercan o los separan, motivando y alterando sus conductas.

El galán y la dama viven el amor en un mundo dramático en el que prevalecen la rigidez de las convenciones sociales. En un mundo así, en el que los amantes se ven separados, vigila. dos y atrapados por las convenciones y normas sociales, es imposible que el auténtico amor aflore en su plenitud. La relación amorosa es reducida a sus esquemas más elementales y son realmente los instintos del varón y de la hembra los que se movilizan ocultos bajo la cobertura social de las frases y de los conceptos.

Las múltiples parejas que en el texto representan la relación galán-dama (doña Beatriz-don Fernando, doña Blanca-don César, doña Esperanza-don Leonel, doña Laura-don Lope, don Enrique-doña Julia, don Diego-doña Marina, etc.) sostienen relaciones amorosas dotadas de tintes románticos en cuanto a la exaltación del amor como sentimiento sublime de la vida, pero también tienen claras muestras de superficialidad, pues el amor más que un compromiso parece un juego.

Doña Luisa (en Monja y casada...) pone en conocimiento de don César, 


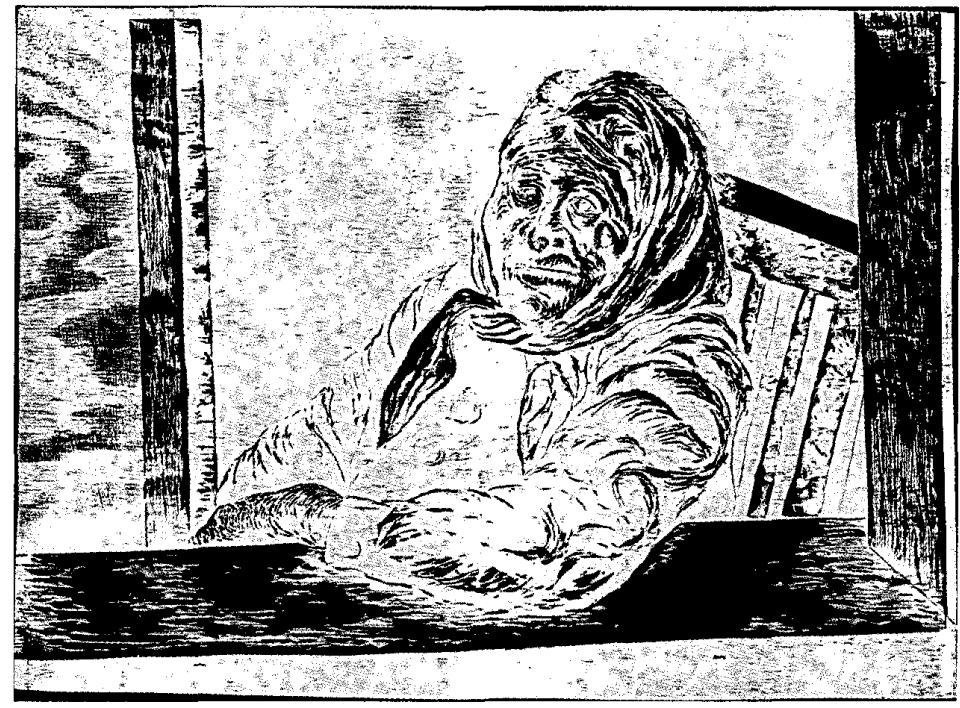

a través de un emisario, el interés amoroso que siente por él dándole una cita para verse en la iglesia del Convento de Jesús María. Don César, halagado por ese amor oculto y desconocido, acude a la cita pero ignorando quién es la mujer que lo ama, cree que esa dama es doña Blanca que se encuentra también en el templo. Don César se enamora rápidamente de la joven y sin embargo al descubrir su error piensa que podría cambiar con facilidad su amor de doña Blanca a doña Luisa, relación que no se lleva a cabo por el resentimiento de doña Luisa hacia el hombre que no ha sabido amarla desde un principio. Don César y doña Blanca se ven obligados a separarse por largos años y se vuelven a reunir en la casa del negro Teodoro, una vez que ha escapado Blanca del claustro, $y$ el amor entre ellos surge otra vez violentamente; impulsando a don César a correr los más grandes peligros por la consecución de ese amor.

Por su parte, don Diego y don Enrique (en Los Piratas...) compiten en número de conquistas amorosas. Doña Ana, la dama en discordia entre don Diego y don Enrique, cambia sus sentimientos amorosos tan pronto como pudiera cambiar de vestido. Acepta el galanteo de don Diego, pero se decide finalmente por don Enrique ya que su linaje y fortuna son más altos; pretende con el matrimonio ganar en posición social, pero una vez que se ve en manos de don Cristóbal de Estada, su raptor y antiguo enamorado, queda conforme con vivir en unión libre con 
él (lo cual sale de todo contexto de la comedia española). Más adelante, cuando vuelve a encontrar a don Enrique, renace su amor por éste y también el despecho y los deseos de venganza por no ser correspondida; por último, dirige su amor una vez más hacia don Diego, al que cree viudo.

Don Leonel, amante de doña Esperanza (en Martín Garatuza) al conocer a doña Catalina siente inflamar su corazón de amor por ella; sin embargo cuando cree perdido el amor de Esperanza para siempre, nacen en su espíritu celos devoradores que lo hacen desesperar.

Los personajes, pues, se aman y se dejan de amar, se juntan y se separan, se dejan llevar a menudo no por la razón ni por los sentimientos sino por los instintos. Se mueven en un mundo en el que prevalecen las reglas del juego convencional del amor. ${ }^{13}$

\section{El personaje femenino \\ y la relación Iglesia-Estado}

En 1867, con la muerte de Maximiliano triunfa definitivamente la causa liberal. Sin embargo Riva Palacio sabía bien que la victoria obtenida con las armas necesitaba la confirmación de las ideas. La reforma significó la secularización de la sociedad, proclamó los principios de la libertad religiosa y la absoluta independencia entre las

${ }^{13}$ Los elementos de la comedia española de capa y espada de los Siglos de Oro que se pueden hallar en el texto de Riva Palacio son numerosos; no nos ocuparemos de ellos en el presen. te trabajo. Este tema lo he desarrollado en mi tesis de licenciatura: "Vicente", 1987. leyes y los negocios eclesiásticos. La misma separación de Iglesia-Estado permite que claudiquen los privilegios de asilo y que desaparezcan los recursos del fuero. El Estado no se mezcla en asuntos de religión, pero tampoco permite que la Iglesia intervenga en cuestiones de orden civil o político. Era evidente que los enemigos vencidos en la guerra se valdrían de todos los medios posibles para impedir que las Leyes de Reforma entraran en funcionamiento $y$, por lo mismo, Riva Palacio comprendía que era necesario trabajar arduamente para convencer a la conciencia popular sobre la bondad y justicia de la Reforma y para inducirla al rechazo de cualquier forma de intolerancia. Entre muchos otros propósitos destinados a defender y justificar la validez de la causa reformista, destaca la composición de sus novelas.

El amplio conocimiento que poseía Riva Palacio sobre la historia colonial le permitió descubrir en este periodo la explicación de muchos de los problemas que hicieron crisis en su época y le permitió a los lectores de sus novelas conocer muchos de los sucesos más notables acaecidos en Nueva España en los siglos XVI y XVII, cuyas secuelas seguían vigentes en el siglo XIX.

En Monja y casada, virgen y mártir, el autor presenta el célebre enfrentamiento entre poder eclesiástico y poder civil representados por el arzobispo Juan Pérez de la Serna: ambicioso, inquieto, intrigante y promotor de la revuelta popular; y el marqués de Gelves: inteligente, impetuoso, rígido, escrupulosamente justiciero y valeroso.

En esta novela se encuentran deta- 
llados todos los pormenores de la lucha en la que la Iglesia, por primera vez en Nueva España, para consolidar su poder y riqueza, se opuso a la autoridad virreinal y se valió de todas sus armas hasta vencer al virrey. El marqués de Gelves defendió vigorosamente su autoridad ante el eclesiástico, pero el pleito culminó con un tremendo tumulto en 1624 en el que el pueblo, incitado por el arzobispo, se levantó en armas contra el poder civil, asaltó e incendió el palacio. El virrey resistió valerosamente pero al final tuvo que tomar asilo en el convento de San Francisco. Aunque el rey dio la razón al marqués de Gelves, éste no volvió a tomar el poder, mientras que el arzobispo perdió el favor del monarca y fue depuesto. Como señala Díaz y de Ovando: "Con gran claridad, con sencillez, con mesura, a través de la novela, el lector popular ha podido enterarse de que la querella entre el marqués de Gelves y el arzobispo era muy parecida a la querella liberal de 1857 , que era justa y nada anticristiana."

Los liberales -agrega Díaz y de Ovando- eran en el fondo católicos, por lo que solamente procuraron la separación de Iglesia y Estado con el fin de obtener el control político dejando que el catolicismo fuera la base espiritual del pueblo. ${ }^{14}$

Los liberales no rechazaron nunca la religión cristiana, pero sí solicitaron al clero que se ocupara de su ministerio y no perdiese el tiempo en asuntos

14 Véase Díaz y de Ovando, "Gran literato", 1958 , pp. 58-60. terrenales que no eran de su competencia.

Riva Palacio plantea el modelo del sacerdote ejemplar en las figuras del padre Antonio en Calvario y Tabor, y en Fray Ángelo en Las dos emparedadas, dignos, virtuosos, fieles a su misión, amantes de la humanidad y particularmente de los débiles y desgraciados. Asimismo, en Martín Garatuza dirá:

Don Juan Pérez de la Serna no era ya como en los tiempos del marqués de Gelves y después de los del gobierno de la Audiencia, un príncipe rodeado de cortesanos y de ostentación. La estrella del prelado comenzaba a nublarse y la tempestad rugía ya por el lado de España [...] El Palacio de Su Señoría Ilustrísima había comenzado a quedar solitario, poco a poco habían ido desertando, uno en pos de otro, los aduladores. Aquella era ya la casa del verdadero obispo cristiano. ${ }^{15}$

Los liberales luchaban por ser ellos quienes organizaran el orden material en la sociedad, un orden que no invadiera el terreno espiritual, pero que sí hiciera respetar el postulado de la libertad de conciencia, principio que tan drásticamente había atacado el orden que los conservadores querían imponer.

Una de las consecuencias de la falta de libertad de conciencia eran las numerosas enclaustraciones de jóvenes que se veían obligadas, por distintos motivos, a ingresar a los conventos sin tener ninguna vocación religiosa. La

${ }^{15}$ Riva Palacio, Martín, 1975, p. 285. 
angustia, el dolor y la impotencia de la monja ante la carencia de libertad era un tema típicamente romántico, que fue expuesto por Alejandro Manzoni en Los novios, y aquí en México ya se habían ocupado del tema, Justo Sierra padre en La hija del judío y Manuel Payno en El fistol del diablo, antes de que Riva Palacio creara el personaje de doña Blanca de Mejía, la víctima y heroína de Monja y casada, virgen y mártir. En esta novela se recoge también otro de los asuntos que debía criticársele al clero: la excesiva e ilimitada influencia que ejercían curas, frailes y monjas sobre los fieles. La supuesta Sor Juana Inés de la Cruz controla la voluntad de doña Beatriz de Rivera, a tal punto que ésta llega a sufrir alucinaciones de ultratumba que la empujan a salvar todos los obstáculos (incluso la oposición de su hermano) para llevar a cabo la construcción de un convento de carmelitas descalzas que la religiosa desea fundar y dirigir en Nueva España. Lucha por apoderarse o por retener las riquezas que están en manos de la Iglesia o de los particulares; la oposición entre el arzobispo y don Alonso de Rivera acarrea finalmente la desgracia a doña Beatriz y al oidor don Fernando de Quezada, enamorado de la joven alucinada.

Por encima de la estructura eclesiástica y de toda estructura social, se sitúa una poderosa institución medieval de orden político más que de carácter cristiano: la Inquisición, que sin tener funciones precisas se permite invadir los dominios tanto del poder eclesiástico como del poder civil.

El papado y la monarquía encontraron en el Santo Oficio el resorte poderoso para afianzar su poder absoluto, por medio del terror al que los pueblos no podían resistir porque lo apoyaban la fuerza de los gobiernos y la innegabilidad del dogma [...] La Inquisición así creada y sostenida, debía ser poderosísima y terrible $[. .$.$] invencible e$ invulnerable, pero como todos los poderes del terror necesitó una palabra que fuera el pretexto de la persecución, y esta palabra, a cuyo sentido ideológico se le dio tanta flexibilidad bajo la cual todo podía caber, fue herejia. ${ }^{16}$

Riva Palacio denuncia en sus novelas los turbios procedimientos de los que se valía la Inquisición para perseguir a judíos, judaizantes, protestantes, piratas, magos, hechiceros, astrólogos, alienados, pillos o pobres infelices que eran denunciados simplemente por venganzas personales. Después de la denuncia se efectuaba la captura y encarcelamiento de los reos, se procedía a la confiscación de los bienes del acusado, que pasaban a las arcas del Santo Oficio y que nadie volvía a ver jamás; seguiría el interrogatorio e interminable proceso, verdadera tortura mental y más tarde el tormento fisico y finalmente la muerte en la hoguera en un solemne Auto de Fe.

Con la censura y denuncia que Riva Palacio hace de la Inquisición, quiere destruir la falsa idea popular, que prevaleció hasta 1812 sobre la bondad del Santo Oficio. El pensamiento liberal debe ofrecer la visión opuesta y presentar a la Inquisición como un mal, enjuiciarla y censurarla como muestra

${ }^{16}$ Riva Palacio, México, 1973, vol. II, p. 430. 
de intolerancia religiosa y racial. Riva Palacio rechaza rotundamente a la Inquisición porque representa la tradición y la ignorancia, que se oponen a la modernidad y al progreso liberal. ${ }^{17}$

Riva Palacio busca asombrar e impresionar a sus lectores mostrándoles bajo otra perspectiva las instituciones que habían exaltado y defendido durante tanto tiempo los conservadores. Así, en sus novelas las imágenes del medievo no producen la nostalgia embellecedora del pasado, típica del romanticismo, sino el horror y el miedo ante la crueldad y deshumanización de la Inquisición.

Sin embargo, es en la figura de la mártir (doña Blanca de Mejía o de las hermanas Carbajal: Isabel, Leonor y Violante), atormentada y sacrificada por el fanatismo religioso, en quien concentra Riva Palacio toda su fuerza para conmover a los lectores. Los mártires de la Inquisición no serán ya tan sólo "los testigos de la fe, sino también los testimonios categóricos del uso perverso de la $\mathrm{fe}^{\text {" }}{ }^{18}$

Así, los lectores no vacilarán en identificarse con las víctimas y sus defensores, identificación que contribuirá al surgimiento en ellos de sentimientos de rechazo y odio a cualquier tipo de intransigencia, así como al respeto por la integridad corporal y psicológica.

Por otra parte se dejará establecido que en un orden de libertad, como

17 Véase Díaz y de Ovando, "Gran literato", 1958, pp. 60-61. 1986.

18 Monsiváis, prólogo a Riva Palacio, Monja,

LA HISTORIA COMO MATERIAL COMPOSITIVO DE LAS NOVELAS pretende ser la sociedad reformista, no podrán volverse a vivir esos tiempos de equívocos, torturas e iniquidades.

\section{El personaje femenino y la relación familia-sociedad}

El pueblo mexicano había concentrado en la Iglesia, en la religión y en sus festividades el fuerte pilar que sostenía a la sociedad y alrededor del cual giraba la vida cotidiana de todos sus componentes. Al triunfo de la Reforma las fiestas religiosas desaparecieron y con ellas una tradición de siglos, dejando en la sociedad un vacío que era necesario llenar con algo.

Al rechazo de la Iglesia como institución fundamental para la sociedad, el liberalismo propone institucionalizar a la familia como eje motor de aquélla. ${ }^{19}$ La columna capital de la familia sería la mujer, sobre cuyos hom. bros se apoyaría todo el peso de la sociedad, guardiana de la honra familiar y de las máximas normas morales.

"La familia, y sobre todo la mujer, son en México modelos verdaderamente evangélicos y tiernos", 20 comenta Riva Palacio en Calvario y Tabor. Ésta, que es su primera novela y la única de tema contemporáneo, podría decirse en pocas palabras que, más allá de su intrincada trama e innumerables peripecias, representa el anhelo de la reunificación de las familias dispersadas por la larga lucha en-

\footnotetext{
${ }^{19}$ Es necesario tener presente también que el matrimonio civil fue instituido por las leyes de Reforma para de hacer más patente la separación entre Iglesia y Estado.

${ }^{20}$ Riva Palacio, Calvario, 1930, vol. I, p. 201.
} 
tre liberales y conservadores-imperialistas.

El final de la novela, el reencuentro de los padres con los hijos (don FelipeLeonor-Jorge y Juan-Margarita-Alejandra) y el matrimonio de las jóvenes parejas (Jorge-Alejandra y EduardoLeonor), que a su vez constituirán nuevas familias, deja grabada para siempre en la mente del lector la imagen familiar como base trascendental para la formación y el desarrollo de la sociedad.

La mujer es elevada a un altar, que es en lo que se constituye -en cierta medida- la religión. De aquí la importancia de la rectitud, de la integridad, de la virtud, y la virginidad de la mujer: "Jorge amaba a Alejandra con esa ternura y esa pureza que hacen de la $\mathrm{mu}$. jer amada una especie de religión..." 21

La mujer, sin embargo, sólo llega a la sublimación a través de la maternidad: "Santo, divino amor de madre, ¿Quién no se descubre con respeto ante una madre? Sea lo que fuere ¿qué madre en el mundo no despierta en el alma la idea de la nuestra?"22

El significado del amor materno es expresado y transmitido por medio de los labios de una mujer a otra mujer en la novela y del personaje femenino a las lectoras, para mayor alcance y penetración del mensaje comunicado: "Oye (dice doña Juana a doña Esperanza) tú no sabes lo que es el amor de una madre para sus hijos, tú no concibes siquiera la idea de este cariño tierno, inmenso, el único desinteresado que hay sobre la tierra, que no exige en su abnegación sublime ni siquiera la correspondencia." 23

La figura de la madre es esencial e insustituible porque a ella se ha conferido la educación y orientación espiritual de los hijos. Riva Palacio, en Calvario y Tabor, opone a dos personajes representativos de la maternidad, la buena madre Margarita frente a la mala madre Matilde. Margarita busca incansablemente al esposo y a la hija perdidos, no la atemorizan peligros ni persecuciones por lograr su objetivo, y al mismo tiempo defender la causa liberal; valentía, nobleza y virtud que la llevan a reunirse finalmente con sus seres queridos; mientras que Matilde, seducida por don Celso Valdespino, no valora en su justa medida la felicidad del hogar y abandona a su esposo y a sus hijos, en un momento de vacilación y temor que la hacen perder para siempre a su familia, el amor que la rodeaba y su posición en la sociedad.

En Martín Garatuza, Riva Palacio volverá a enfatizar el papel de la madre respecto a sus hijos confrontando la ạctitud de doña Juana de Carbajal hacia su hija Esperanza y la de doña Catalina de Armijo con su hija Catalina. Doña Juana educa a su hija dentro de los más altos principios cristianos y anhelos de libertad, la enseña a amar, confiar y esperar; en su mismo nom. bre sintetiza el ideal aprendido: esperanza, y es esta esperanza cristiana, siempre viva, la que la salva de todos los obstáculos y contratiempos, aunque su madre haya muerto, y la hace triunfar sobre sus enemigos para lle-

${ }^{23}$ Riva Palacio, Martín, 1975, vol. I, p. 16.
21 Ibid., vol. II, p. 387.

22 Ibid., vol. II, p. 383. 
varla directamente a la dicha final. Doña Catalina por su parte hace concebir a su hija gran interés por los lujos y riquezas banales de la vida, incitándola incluso a perder su inocencia y virginidad a cambio de dinero, actitud que labra su desgracia y le quita toda posibilidad de felicidad en la vida. Catalina, al sentir por vez primera el amor, el verdadero amor por un hombre (don Leonel) y reconociendo su situación, dice a su madre:

Vos sois la que habéis comerciado conmigo, la que entregasteis mi virtud y mi inocencia, la que procuró corromper siempre mi corazón y mancillar mi espíritu como mancillasteis mi cuerpo. Sí, vos señora que no habéis sido para mí una madre, porque no habéis visto en mí una hija sino una mercancía para enriqueceros [...] Yo también he adquirido a costa de mi honra esas malditas riquezas cuyo peso no conocía hasta este momento, porque me siento renegada señora, porque abro mis ojos a la voz de la verdad, porque comprendo que soy rica pero que valgo menos que la esclava más infeliz, porque con mis tesoros, más que los que poseo no conseguiría volver a la inocencia, ni a la virtud, porque pobre, miserable y cubierta de harapos quizá conservaría la ilusión de ser la esposa de un caballero, no tendría que ocultarle mi nombre, ni mi historia, no bajaría mi frente con vergüenza delante de esa Esperanza a la que hemos hecho desgraciada, y que lo confieso a mi pesar, es más digna del amor de don Leonel que yo. Yo que podré comprar amantes [...] pero nunca inspirar una pasión ardiente y pura, una pasión noble. ${ }^{24}$

${ }^{24}$ Ibid., vol. II, pp. 249-250.
Si bien es cierto que el núcleo familiar está cimentado en la figura de la madre no deja de ser menos indispensable la figura paterna, cuya misión básica es la de dar nombre y posición social a la esposa y a los hijos, pero que a diferencia de la madre es incuestionable en todas circunstancias. Martín dice a doña Esperanza:

Vuestro padre vive, pero en estos momentos está moribundo y le he hablado de vos. Quiere veros, os reconoce, os nombra su heredera, me encarga que os lleve junto a su lecho de muerte. Iréis?

-Nunca $[. .$.$] nunca iré a ver al hom-$ bre que deshonró, que hizo la desgracia de mi pobre madre, que la abandonó.

-Pero ese hombre es vuestro padre, os llama, está arrepentido y vos no tenéis el derecho de acusarle, ni de juzgarle siquiera.

-Tenéis razón, tenéis razón, es mi padre -exclamó sollozando Esperan$\mathrm{za}^{25}$

La institución familiar erigida como eje social es reforzada constantemente por medio de las rígidas normas morales que atañen a todos los miembros de la familia.

El personaje femenino

y el sistema de la doble referencialidad

Las novelas de Riva Palacio de tema colonial están escritas de acuerdo con una doble temporalidad: el tiempo de la colonia y el tiempo del narrador omnisciente (siglo XIX) detrás del cual se oculta el autor, historiador del perio-

${ }^{25}$ Ibid., vol. 1, p. 81. 
do colonial. La convivencia de los dos tiempos: presente y pasado en un mismo discurso narrativo, ocasiona que los límites del doble referente que maneja el texto y sobre el que se sostiene se diluyan confundiendo uno con otro.

La visión que tiene Riva Palacio de la colonia, que procura transmitir por medio de sus novelas, es la de un

periodo tranquilo de crecimiento, interrumpido apenas por tumultos locales y sin consecuencias, o por invasiones prácticas en las costas, que no tenían más resultado que el saco o destrucción de algún puerto. La vida de la colonia se deslizaba sin ruido y sin brillo. Las noti. cias de la corte que una o dos veces al año llegaban con las flotas, las funciones religiosas, los actos literarios de la universidad y algunas veces las ejecuciones de justicia o los Autos de $\mathrm{Fe}$, eran los acontecimientos que turbaban la monotonía de aquella existencia, pero bajo aquella calma y aquella aparente tranquilidad se formaba un pueblo. ${ }^{26}$

Época de mestizaje racial y cultural, en la que se "formó la individualidad social y política que sintiéndose viril y robusta proclamó su emancipación en $1810 " .27$

Ahora bien, si la colonia representó el entrelazamiento de dos culturas que hicieron nacer a un nuevo pueblo, también significó un periodo nefasto en el que se negaron los derechos más elementales de la humanidad, en el que la miseria de las mayorías dio lugar al esplendor y riqueza de la Iglesia y la corona, en el que la libertad fue nuli-

26 Riva Palacio, México, 1973, vol. It, p. 12.

${ }^{27}$ Ibid., vol. II, p. 8. ficada y únicamente existió en la clandestinidad.

Para Riva Palacio fue tarea vital mostrar el doble carácter de la etapa colonial pues de esa duplicidad provenían las dos corrientes dominantes del siglo XIX (liberalismo y conservadurismo) enfrentado por más de medio siglo en sus respectivas modalidades.

Las circunstancias habían sido transformadas por el transcurso del tiempo, pero ambas habían heredado las raíces de la colonia. Así, Riva Palacio construye su novela colonial bajo la mira de un eje oposicional que podría identificarse de la siguiente manera:

Virreinato-Colonia
Arriba-Abajo
No válido-Válido
Negativo-Positivo
Poder español absoluto-Mestizaje
Riqueza-Miseria
Esclavitud-Libertad
Estatismo-Dinamismo
Apariencia-Realidad
Oscuridad-Luz
Silencio-Ruido

Como consecuencia y prolongación de lo anterior, cortesponderá al siglo XIX:

Colonialismo-Independencia

Tradición-Modernidad

Retroceso-Progreso

Conservadurismo-Liberalismo

Puede decirse entonces que cuando Riva Palacio se refiere a la colonia está planteando también la problemática del siglo XIX, originada en el pasado colonial. Al mismo tiempo que de- 


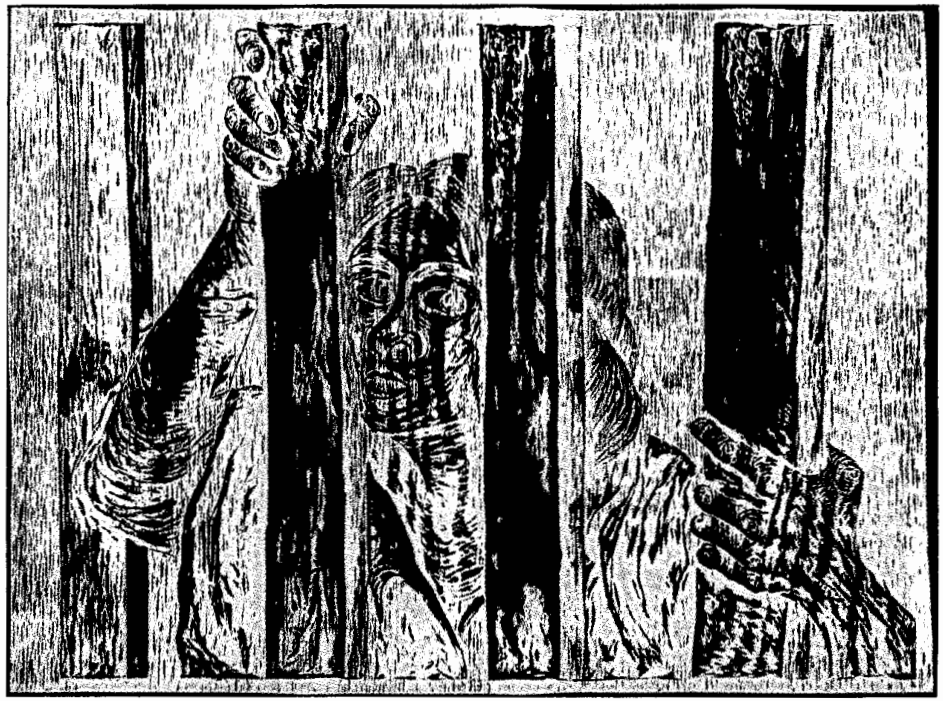

nuncia las fallas de los tres siglos de dominación española, niega la validez de sus herederos y previene la repetición de males semejantes.

El sentimiento de libertad, concepto de primera instancia para el romanticismo, está latente en todas su novelas, sus defensores son múltiples; pero la causa en pro de la libertad no sólo es asunto de hombres sino también de mujeres. Mujeres que luchan por ella y enseñan a amarla a sus hijos; mujeres que como Margarita, doña Juana o doña Fernanda sienten inundados sus espíritus de anhelos patrios de independencia y libertad, vigorosas y valientes para pelear por sus ideales. La que está dispuesta a correr todos los peligros necesarios en auxilio de su nación, como el centro y pilar de la so- ciedad, es figura de primerísimo orden para el optimismo liberal por alcanzar la edad de oro. No obstante la mujer, modelo liberal, ángel del porvenir como la llamara Justo Sierra, será al mismo tiempo quien conserve vigentes las normas morales más rígidas y tradicionales de la sociedad.

La imagen del mundo de Riva Palacio comunicada a través de sus novelas se expresa en el texto en dos niveles: uno explícito o directo, el otro indirecto o sugerido; con el primero niega y prohíbe, con el segundo afirma y ordena. ${ }^{28}$

La cosmovisión colonial, su prolongación y consecuencias en el siglo XIX

${ }^{28}$ Todorov, Simbolismo, 1981, p. 12. 
expuestas por la intriga y peripecias de la acción de las novelas, niega el derecho que se adjudicaron la corona española y la Iglesia para disponer de las vidas, riquezas y conciencias de los habitantes de Nueva España y al mismo tiempo prohíbe la intransigencia racial, política y religiosa.

Ahora bien, este mensaje es explícito y directo, pero de él se desprende un segundo mensaje implícito insertado en el directo por el cual se afirma la validez del código moral planteado y se ordena a la mujer su cabal cumplimiento para el desarrollo del bienestar colectivo y la conservación de la sociedad.

La enseñanza moral que se trasluce y se refuerza constantemente 'en el texto nos permite considerar que, si bien es cierto que la obra de Riva Palacio tiene una notoria función educadora en todos los órdenes posibles: estético, político, social, histórico, filosófico y religioso, su especificidad debe buscarse en el mensaje moral, dirigido particularmente a la mujer.

\section{BiBLIOGRAFÍA}

-Altamirano, Ignacio M., Literatura nacional, Porrúa, México, 1949.
-Díaz y de Ovando, Clementina, "Un gran literato liberal, Vicente Riva Palacio", Anales del Instituto de Investigaciones Estéticas, núm. 27, 1958.

-Ferraras, Juan Ignacio, Fundamentos de sociología de la literatura, Cátedra, Madrid, 1970.

-Lotman, Yuri, Estructura del texto artústico, Itsmo, Madrid, 1970.

-Riva Palacio, Vicente, Monja y casada, virgen y mártir, Porrúa, México, 1974 (Colección de Escritores Mexicanos, 19). , Monja y casada, virgen y mártir, prólogode Carlos Monsiváis, Océano, México, 1986.

Martín Garatuza, Porrúa, México, 1975 (Colección de Escritores Mexicanos, 20).

, México a través de los siglos, vol. II, "El virreinato", Editora Nacional, México, 1973.

chez, México, 1930.

Calvario y Tabor, León Sán-Rivera, Jorge B., El folletín y la novela popular, Centro Editor de América Latina, Buenos Aires, 1968.

-Solórzano Ponce, María Teresa, "La propuesta ideológica de la novela mexicana de folletín en el siglo XIX: la novela de Vicente Riva Palacio", tesis de maestria en Letras Mexicanas, unam, México, 1991. "Vicente Riva Palacio ante la vida teatralizada de México en el siglo xIX", tesis de licenciatura en Letras, UNAM, México, 1987.

-Todorov, Tzvetan, Simbolismo e interpretación, Monte Ávila, Caracas, 1981. 